Incorporating the Online Encyclopedia of Chemical Engineering Equipment Into Your Course Activities

Dr. Susan M. Montgomery, University of Michigan

Dr. Susan Montgomery is the G. Brymer Williams Collegiate Lecturer and Undergraduate Program Advisor in the Chemical Engineering Department at the University of Michigan. She holds a BSE ChE degree from the University of Michigan and MSE and PhD ChE degrees from Princeton University. 


\title{
Incorporating the Online Encyclopedia of Chemical Engineering Equipment Into Your Course Activities
}

\begin{abstract}
Students in chemical engineering courses often bemoan the lack of information regarding actual chemical engineering equipment in our curricula. To address this critical need in our curricula our laboratory has devoted twenty years to the development of an online visual encyclopedia of chemical engineering equipment, aimed at chemical engineering undergraduate students. This encyclopedia provides students with a basic understanding of what chemical engineering equipment looks like and how it works. In our paper we describe the encyclopedia and present ways to incorporate the encyclopedia into core Chemical Engineering courses.
\end{abstract}

Many pedagogical tools to enrich chemical engineering courses are available, but faculty with limited time often don't fine the time to implement these tools into these courses. In this paper we provide suggestions to enrich existing assignments and course activities, which will lower the barrier to action. This will allow faculty to easily expose students to real chemical engineering equipment through the use of the Encyclopedia, enriching their educational experience and better preparing them to become chemical engineers.

\section{History of Encyclopedia}

The idea for the visual encyclopedia of chemical engineering equipment was born 30 years ago when the author was completing her undergraduate studies and realized that she didn't have a solid understanding of what chemical engineering equipment looked like or how it worked. When she began a faculty position in 1993, one of her first NSF grants (NSF DUE 9555125) supported the development of a CD multimedia materials for the introductory chemical engineering course, including the Visual Encyclopedia of Chemical Engineering Equipment. The modules, developed largely by scores of chemical engineering undergraduate students, were included in a CD-ROM that accompanied the $3^{\text {rd }}$ edition of Felder and Rousseau's Elementary Principles of Chemical Processes ${ }^{1}$. The reactors portion was included in the $4^{\text {th }}$ edition of Fogler's Elements of Chemical Reaction Engineering ${ }^{2}$. Many editions of the CD version of the Encyclopedia have been distributed by the CACHE Corporation through their website, cache.org, to faculty interested in implementing it into their courses. Companies have bought it and used it as part of their technician training, and individual students have requested copies of the CD as well.

As with many useful pedagogical materials, though, if faculty do not give assignments that require the use of the encyclopedia, it's doubtful that a student would use it. In addition, installing the encyclopedia on college computer networks to make it available to students presented another hurdle to implementation. After the NSF funding was exhausted, our Chemical Engineering department generously has supported a few undergraduate students a year to help produce an online version of the encyclopedia, available at encyclopedia.che.engin.umich.edu , which is now easily available to faculty and students alike. In addition, engineering technicians 
have reported to the author using the encyclopedia to determine the best type of equipment to use for their purposes.

\section{Description of encyclopedia}

The main page of the encyclopedia, shown in Figure 1, displays the nine categories of equipment. The table in the Appendix lists the over one hundred types of equipment within these categories.

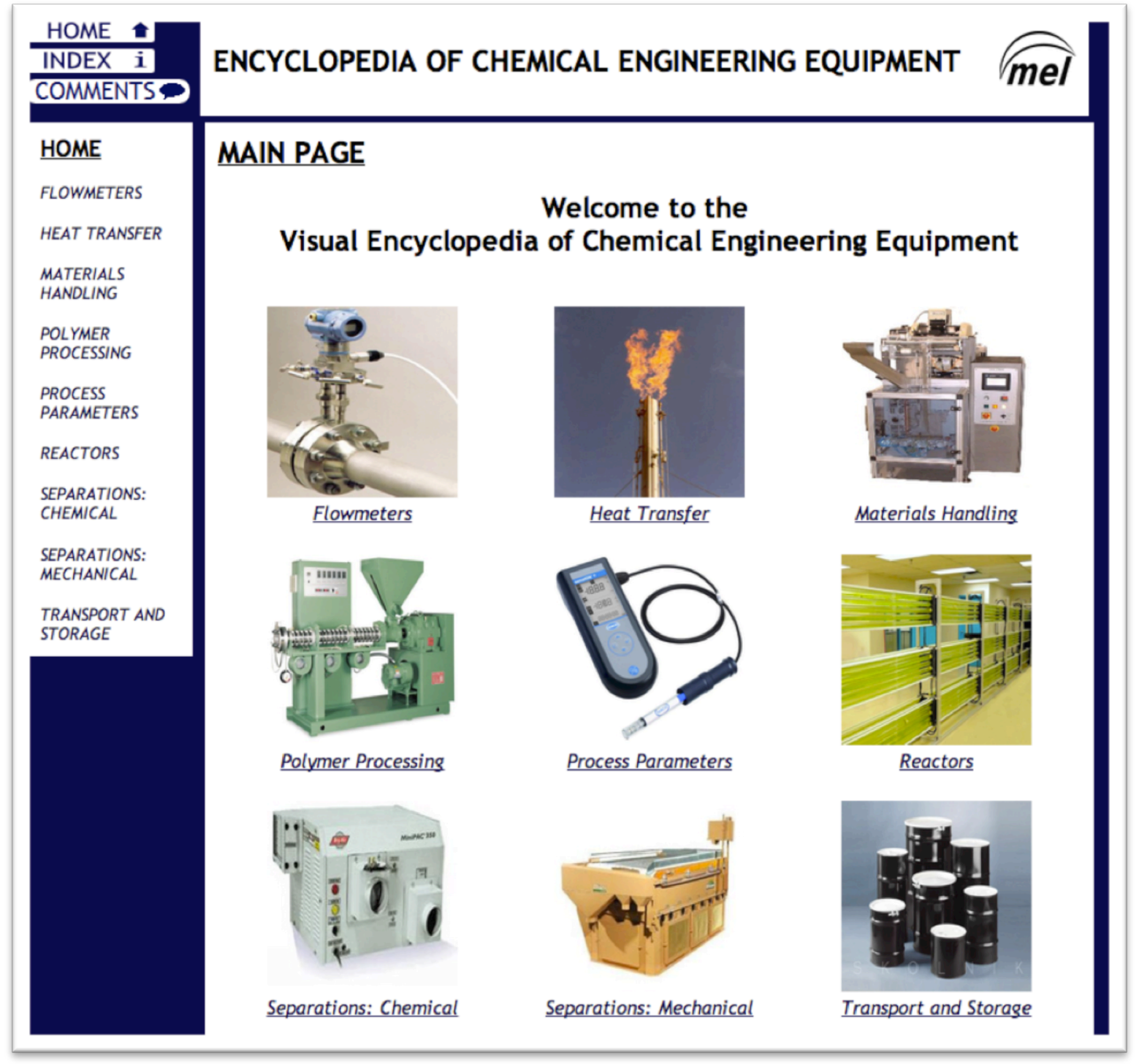

Figure 1. Encyclopedia of Chemical Engineering Equipment home page 
At the heart of the Encyclopedia are photographs of actual equipment, schematics, and animations showing how the equipment works, and pictures and descriptions of applications of the equipment in a wide variety of areas. With a few exceptions of photographs taken in-house, all photographs and many videos were obtained with permission from equipment manufacturers, or from textbook and trade journals. Some of manufacturers also generously reviewed and gave us feedback on the relevant pages of the encyclopedia. Some faculty have also offered their services to review certain page related to their research area, and they are acknowledged in the relevant pages. Other videos and schematics describing how equipment worked were developed in-house.

For each type of equipment the Encyclopedia provides students with information in the following areas: General Information, Equipment Design, Usage Examples, Advantages / Disadvantages, and References. Examples of some of these sections are shown in Figures 2 through 6. For example, the general information portion of the Water Deluge Systems section, shown in Figure 2, gives a general overview of the types of systems that exist.

\section{GENERAL INFORMATION}

Water is the most naturally abundant and widely used extinguishing substance. It extinguishes fire by cooling.

There are three main types of water deluge systems, components of which are shown below. From left to right, they are: fine water spray systems, sprinkler systems, and water spray systems.
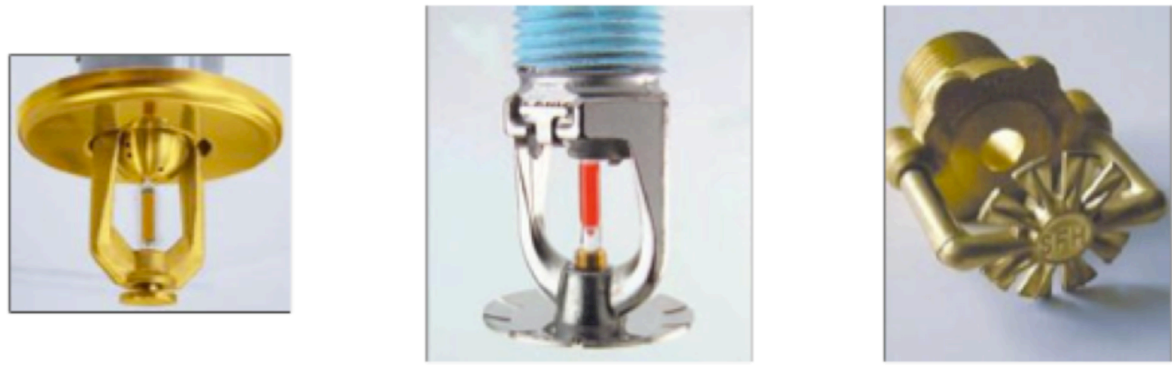

(Courtesy of Minimax GmbH \& Co. KG, Bad Oldesloe, Germany )

Figure 2. General Information portion of the Water Deluge Systems section

The Equipment Design portion of each section includes key information about how the equipment works. The Equipment Design portion of the Oval Gear and Impeller Flowmeter section, for example, shown in Figure 3, includes an animation developed in-house to show how oval gears measure flowrates. Note in some cases two portions are combined, as the General Information and Equipment Design portions here. 


\section{OVAL GEAR \& IMPELLER}

\section{GENERAL INFORMATION/EQUIPMENT DESIGN}

Jval gear meters and impeller meters, shown below, operate in the same manner, but differ in the shape of the gears. Fluid flowing through the measuring chamber causes the gears to turn, displacing an exact volume of fluid. A magnetic or mechanical device counts the number of turns, determining the volumetric flowrate.

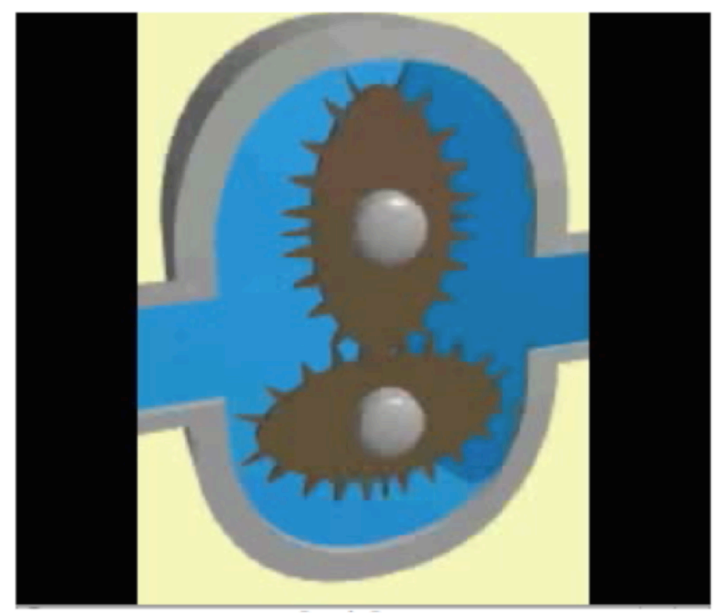

Figure 3. General Information / Equipment design portion of the Oval Gear and Impeller Flowmeters section

The Equipment Design portion can also include graphics and photographs of actual chemical engineering equipment, as show in Figure 4, from the Equipment Design portion of the Plate and Frame Heat Exchangers section.

The Usage Examples portion shows the equipment in actual use, such as the Plug Flow Reactor Usage Example portion shown in Figure 5. The Advantages/Disadvantages portion gives pros and cons of that type of equipment compared to others. In Figure 6, for example, the advantages and disadvantages of roots vacuum pumps are shown, which could be compared to those of other types of vacuum pumps. 


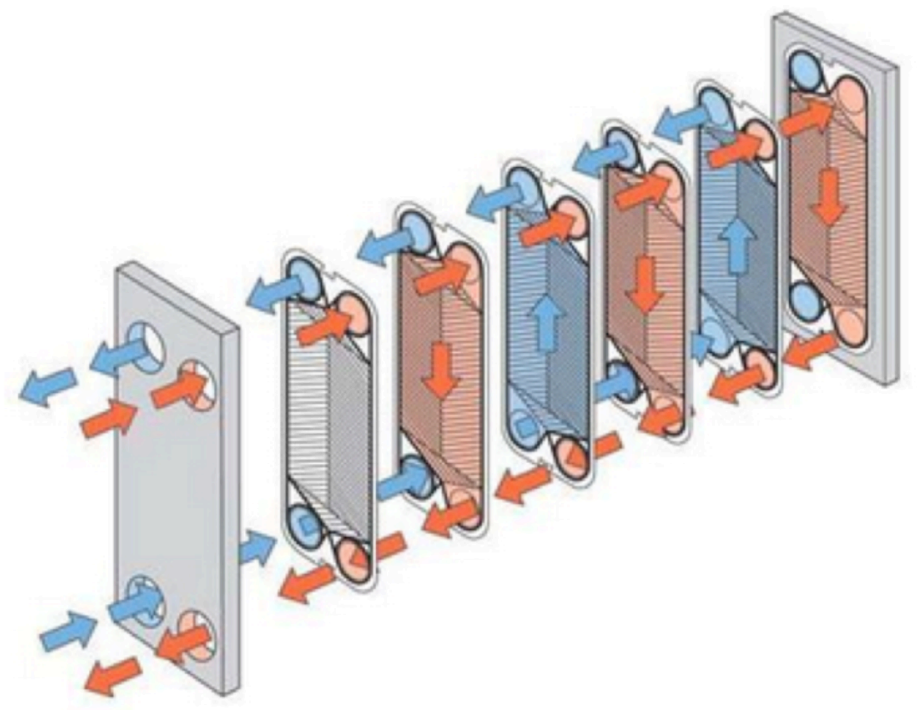

(Copyright Alfa Laval, Richmond, VA)

The pictures shown below are examples of double wall heat exchangers.
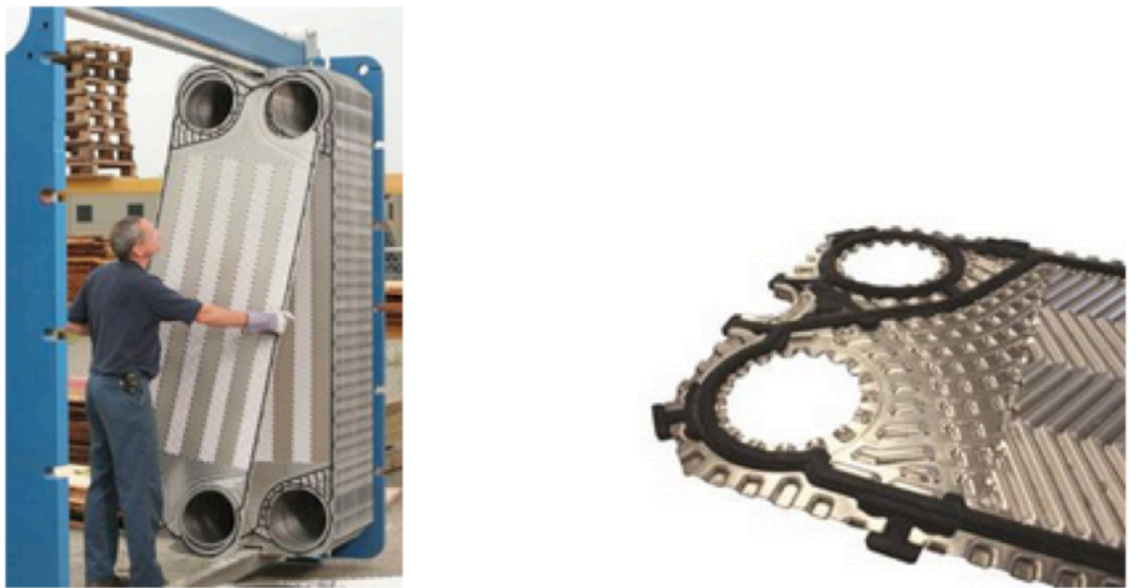

(Copyright Polaris Plate Heat Exchangers, Tinton Falls, NJ)

Figure 4. Diagrams and photographs in the Equipment Design portion of the Plate and Frame Heat Exchangers section. 


\section{USAGE EXAMPLES}

Plug flow reactors have a wide variety of applications in either gas or liquid phase systems. Common industrial uses of tubular reactors are in gasoline production, oil cracking, synthesis of ammonia from its elements, and the oxidation of sulfur dioxide to sulfur trioxide. Pictured below is a tubular reactor used in research on the oxidation of nitrogen compounds. It reaches temperatures of $800-1100^{\circ} \mathrm{C}$.

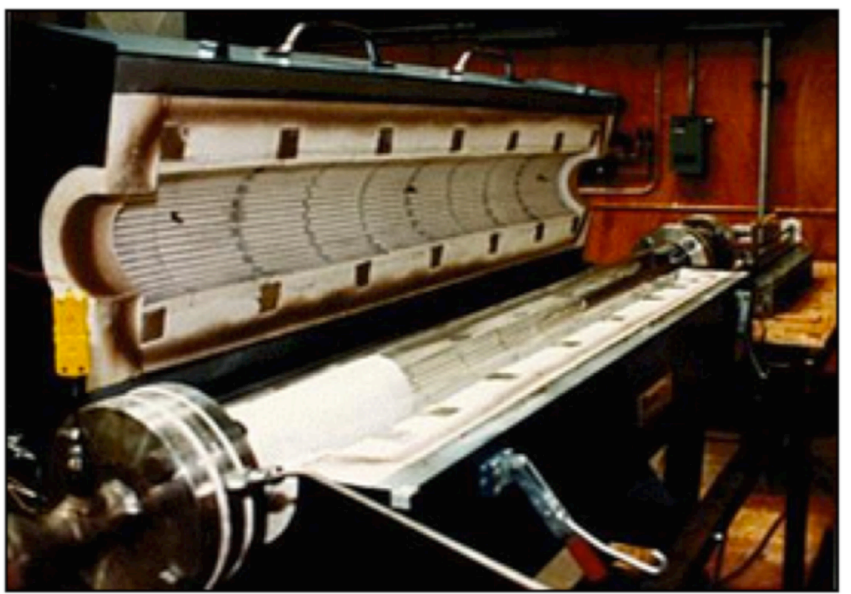

(Copyright Robert Hesketh, Rowan University, Glassboro, NJ)

Figure 5. Usage Examples portion of Plug Flow Reactors section

\section{ADVANTAGES}

- Able to achieve high vacuum levels and handle large flow rates

- Relatively low noise level

- Available in small sizes suitable for laboratory applications

- High compression ratios per stage

- Reliable

Return to Top

\section{DISADVANTAGES}

- Sensitive to contamination

- High service requirement

- Intolerance for liquid slugs

- Need to select a compatible lubricant

- Low tolerance for fouling

- Limited materials of construction

Figure 6. Advantages/Disadvantages portion of Roots Vacuum Pumps section

\section{User Response}

Student response to the encyclopedia has been mixed. Some students greatly appreciate it and use it frequently, others don't appreciate the information provided therein. In some cases because many of the times it's assigned it is as part of a group project, we have some seniors that don't seem that aware of the encyclopedia's existence even, or what a wide range of equipment is covered by the encyclopedia. Faculty have generally been quite positive and have appreciated having the information in preparing course materials. We have also shared this with some of our 
departmental industrial contacts, who have been overwhelmingly positive, and have gotten great feedback. Companies that provide us with materials often suggest edits that help improve the encyclopedia.

\section{Implementing the encyclopedia in chemical engineering courses}

In this section we describe recommendations to easily incorporate the Encyclopedia into chemical engineering courses through small changes to likely already existing course activities.

Preparing and delivering lectures - The Encyclopedia is an excellent resource for faculty who are not familiar with equipment to acquaint themselves with the operation of chemical engineering equipment in preparing for teaching a course. In addition, the schematics, photographs and videos can be incorporated into lecture slides to make their lectures come to life. For example, when the author taught the Mass and Heat Transfer course she found the Encyclopedia an invaluable source of graphics and animations.

Addendum to homework assignments - When assigning homework problems involving chemical engineering equipment, faculty can add an additional question that require students to research chemical engineering equipment and have a better understanding of how it operates. Felder and Fogler's textbooks ${ }^{1,2}$ make this easier by including references to the encyclopedia within their homework assignments and main text. In our Process Controls class, for example, a bonus question in a homework assignment involved reviewing the Encyclopedia to find instruments available to measure liquid level, and describing briefly how one of them works.

Extra credit problems on exams - To encourage students to interact with the Encyclopedia to learn about the equipment relevant to their courses, faculty can announce that a simple extracredit problem regarding the operation of those types of equipment will be included on an exam. The questions need not be very detailed and can easily be written through a quick overview of the encyclopedia.

Required reference for existing projects - If the course already includes a project with references, it is simple to enrich the experience by requiring students to cite relevant pages of the encyclopedia as one of the project references.

Design projects - In design courses students often include unrealistic designs of equipment because they do not understand how the equipment works. The author herself recalls designing a 600 -foot tall weeping wall separation column in an early version of her senior design project. Encouraging students to refer to the encyclopedia to familiarize themselves with the equipment they are designing and the advantages and disadvantages sections in particular, can help yield more realistic designs. Note that the encyclopedia is not interactive in that it cannot be integrated with process simulation programs such as HYSIS and ASPEN.

\section{Dos and Don'ts}

In this section we include some suggestions for faculty who wish to incorporate the Encyclopedia into their courses: 


\section{Do}

- Demonstrate the Encyclopedia in class so students can see what it looks like and how to navigate through it.

- Include a citation to the Encyclopedia when including visuals in your slides to model proper referencing (citation to be included in final version)

- Include a link to the Encyclopedia from your course website to facilitate access.

- Encourage students to use the Encyclopedia during conversations with students about equipment in general.

- Teach students how to reference web pages if you include accessing the Encyclopedia as a requirement to projects. One proper citation would read (citation to be included in final version)

\section{Don't}

- Assign reading the Encyclopedia as a volunteer activity and expect students to do it. As with many useful activities, if it's not worth points the students won't do it.

- Make any extra-credit questions on exams so difficult that students feel they need to spend inordinate amounts of time memorizing minutiae of advantages and disadvantages of equipment, for example. The goal should be for students to appreciate the value of the encyclopedia so they might consider referring to it in future occasions.

\section{Current and Future Work}

While all modules of the encyclopedia have been ported to the web, the encyclopedia can never be considered completed. Students working on independent study projects continue to update the encyclopedia using new reference material, including trade journals and textbooks, and checking manufacturer's websites for additional photographs and information. In addition, they are working on new sections that address specific applications, starting with a Safety section that will make it easier for students to find references to process equipment typically used in process safety, with links to existing pages, and also include new material such as Personal Protective Equipment.

For the primary author the primary task, besides reviewing the students' updates, is the dissemination of information about the encyclopedia to help bring it to the attention of chemical engineering students and faculty, as well as industrial users for training of technicians, and the general public. This will include uploading the videos produced in-house to YouTube, and producing articles that reach students and faculty more directly, such as materials disseminated to AIChE student chapters and through the ASEE Chemical Engineering division. Additional suggestions are gratefully accepted.

Some have suggested the idea of allowing others to make contributions to the encyclopedia, in an openware, "Wiki" style, or to make it interactive and connect it with process simulation software. Unfortunately at this time we are not in a position to manage such endeavors. 


\section{Acknowledgements}

The author would like to gratefully acknowledge the dozens of chemical engineering students who have worked on the encyclopedia over the past twenty years. This work would not have been possible without NSF DUE grant 9555125, and later the financial support of the (school) chemical engineering department. Finally, she thanks her colleagues for implementing the Encyclopedia into their courses, and the reviewers of this paper for their helpful suggestions.

\section{References}

1. Felder, Richard M. and Ronald W. Rousseau, Elementary Principles of Chemical Processes, $3^{\text {rd }}$ ed., John Wiley \& Sons, 2000.

2. Fogler, H. Scott, Elements of Chemical Reaction Engineering, $3^{\text {rd }}$ ed., Prentice Hall PTR, 1999. 


\section{Appendix - Types of Equipment in Encyclopedia of Chemical Engineering Equipment}

Flowmeters
Differential pressure
Mass
Open channel
Positive displacement
Velocity
Heat transfer
Boilers
Chimneys
Condensers
Cooling towers
Cryogenics
Flares
Furnaces and Kilns
Heat exchangers
Refrigeration

Materials Handling
Batching
Hoppers
Mixers
Presses
Scales
Size enlargement
Size reduction
Tablet coating

\section{Polymer Processing}

Blow molding

Blown film

Calendering

Extruders

Fiber spinning

Injection molding

Powder coating

Rotational molding

Thermoforming

Process Parameters

Analyzers
Chromatography

columns

Colorimeters

Conductivity meters

Detectors and monitors

Humidity measurement

Level measurement

$\mathrm{pH}$ measurement

Pressure measurement

Refractometers

Sight flow indicators

Spectrometers

Temperature

measurement

Turbidimeters

Viscometers

\section{Reactors}

Batch

Continuous stirred tank reactors

Fluidized bed reactors

Fixed film

Moving bed

Packed bed reactors

Plug flow reactors

Semi-batch

Slurry

Trickle bed

Bioreactors

Chemical vapor deposition reactors

Fuel cells

Nuclear reactors

Oxidizers

Catalysts

Separations: Chemical

Absorbers

Adsorbers

Biofilters

Crystallizers
Dehumidifiers

Distillation columns

Dryers

Evaporators

Extractors

Humidifiers

Ion exchange columns

Membranes

Strippers

\section{Separations:} Mechanical

Centrifuges

Cyclones / hydrocyclones

Electrostatic precipitators

Filters

Gravity separators

Mist eliminators

Screeners

Steam traps

Thickeners / clarifiers

Transport and Storage

Actuators

Aerators

Chlorinators

Compressors

Conveyors

Deluge systems

Drums

Fans

Nozzles

Ozonators

Pipes

Pumps

Seals

Tanks

Turbines

Vacuum pumps

Valves 